\title{
Engineering Design Coaches: Faculty or Grad Students?
}

\author{
Daryl Caswell \\ Faculty of Engineering \\ University of Calgary \\ djcaswel@ucalgary.ca
}

\author{
Clifton Johnston \\ Faculty of Engineering \\ University of Calgary \\ johnston@enme.ucalgary.ca
}

\author{
Rod Fauvel \\ Faculty of Engineering \\ University of Calgary \\ fauvel@enme.ucalgary.ca
}

\author{
Diane Douglas \\ Faculty of Engineering \\ University of Calgary \\ ddouglas@ucalgary.ca
}

\author{
Marjan Eggermont \\ Faculty of Engineering \\ University of Calgary \\ meggermo@uclagary.ca
}

\begin{abstract}
The Boyer Commission Report on Undergraduate Education of 1998 calls for universities to make a greater commitment to the training and involvement of graduate students as teachers. Should this apply to the Engineering Design environment? Are there issues of responsibility, technical expertise and professional experience that exclude graduate students from the role of design coach? At the University of Calgary, in eight years of involvement with both faculty and graduate students as design coaches, we have come out strongly in favour of our graduate students. In fact, in most cases, graduate students get as good or better results from the undergraduate students than the faculty members. This paper explores the reasoning behind this result and the environment that produces the result.

The focus is on the nature of the design environment as one of participatory inquiry. Perhaps the most significant feature of participatory inquiry is the creation of an environment in which all members (students and design coaches) are simultaneously student and teacher. In fact, the coaches regularly remark that they learn more about design by being a coach than through any other experience they have had. The faculty members, however, are often handicapped by their expertise. This is partly due
\end{abstract}

of the narrow focus of their research area and partly due to the assumption by the students that the knowledge of the faculty member is more important than their own.

In a participatory environment, the properly trained and supported graduate student is better able to develop a relationship with the student design teams that fosters the types of thinking and activity necessary for effective design work. This includes responding appropriately to vague, poorly defined problems that characterize design work, developing and defending independent solutions to open-ended problems, and communicating effectively on several levels. The coaches are not required to become experts on each of the projects they coach and in fact, are encouraged to stand back and allow the students become the experts for their projects. Further, the mandate of the coaches is to allow students to uncover the answers regarding design process even if it means they may flail somewhat. The students begin to take ownership of their knowledge and authentic design work results.

\section{Introduction}

University education in North America has undergone significant change since the mid 1990 's. In general, there has been a move to revamp undergraduate education in order to provide a broader range of training within each 
discipline and to engage students in taking responsibility for their own learning. The goal is to produce more well-rounded, more creative thinkers and life long learners. The main tool for supporting the change is inquiry-based learning. Within engineering, this transformation is reflected in the push by $\mathrm{ABET}$ and $\mathrm{CEAB}$ to ensure that every engineering student is provided with a real world, open-ended, team oriented design experience before graduation.

The introduction of a significant design experience into the engineering curriculum requires a very different environment than the traditional lecture, lab and tutorial common to most engineering courses. The challenge of creating a design environment is made more difficult by the current trend toward very large classes. The combination of the increased faculty/student interaction required by inquirybased learning and the greater number of students requiring a higher level of interaction has put a considerable strain on the ability of faculty members to meet the demands of the twenty first century classroom.

For engineering design in particular, there is a long held belief that design should ideally be taught by a professional engineer who is experienced in real world design. To leave the task to faculty and/or graduate students who are trained only in research is considered to be less than ideal. This further complicates the need to optimize the teaching resources available within an engineering faculty.

This paper looks at the possibility of using graduate students as design coaches (under the supervision of the instructor) for large classes (over 25 students). Since initiating the practice eight years ago, the authors have found the benefits outweigh the drawbacks by a considerable margin. The primary resource for support of the practice is the 1998 Boyer Commission Report Reinventing Undergraduate Education which is the catalyst for much of the change taking place in university teaching today [6].

\section{Engineering Design Before Boyer}

The conventional view of engineering design is as a culmination of an engineering education. The integrative nature of design and the need for engineers to be involved in all aspects of design (from conceptualizing to prototyping) implies that design instruction should be carried out by individuals who have experience in the broad scope of real world engineering design. While the skills of the designer lie more in synthesis than in analysis [1], most academic engineering researchers have expertise in a narrow range of analytical engineering knowledge and not in the kind of synthesis required in design.

In fact, since the Grinter Report of 1955, which established the practice of delivering engineering education through the math/science mode of lecture, lab and tutorial, the number of academics who are experienced in design has declined. Although the Grinter report clearly identifies design problems as one of the cornerstones of the engineering profession, the wholesale adoption of the math/science focus did not provide a suitable environment for supporting design education [4]. By 1990, most engineering programs offered design as an afterthought, if at all.

\section{The Boyer Report and the Difficulties of Engineering Design}

The 1998 Boyer Commission Report was the culmination of an extensive survey of undergraduate teaching practice in American research universities. Dr. Boyer, President of the Carnegie Foundation for the Advancement of Teaching, urged the commission to address the fact that the expectations for post-secondary education had changed significantly in recent years. In spite of the need for university education to meet new challenges, undergraduate education remained little different from high school level learning. The commission developed a list of recommendations for change in undergraduate education:

1. Make research-based learning the standard

2. Construct an inquiry-based freshman year

3. Build on the freshman foundation

4. Remove barriers to interdisciplinary education

5. Link communication skills and course work

6. Use information technology creatively

7. Culminate with a capstone experience

8. Educate graduate students as apprentice teachers

9. Change faculty reward system

10. Cultivate a sense of community

The goal was to elevate university learning to emphasize inquiry, investigation and discovery in undergraduate classrooms and in graduate apprenticeships.

The vision of the Boyer Report provides a significant incentive for the rejuvenation of design 
in undergraduate engineering programs. However, there remain a number of concerns:

1. The conviction that engineering design should be taught by professional engineers experienced in real world design.

2. The difficulty in providing an inquirybased, design experience in a large class environment where a higher level of instructor/student interaction is required.

3. The inexperience in design of the typical graduate student tutorial assistant required for the operation of a large class.

The key to integrating the recommendations of the Boyer Report with these concerns lies in differentiating between engineering design practice and engineering design education.

\section{Engineering Design Practice vs Design Education}

The goal of engineering design practice is to create practical and safe design solutions through the integration of fundamental engineering principles. The goal of engineering design education is to create the environment in which engineering students learn to solve open-ended design problems by integrating and employing their knowledge of fundamental engineering principles.

The assumption inherent in the post-Grinter and pre-Boyer engineering schools was that learning to design could only occur under the specific guidance of a qualified instructor in a lecture/lab/tutorial environment. Engineering design theory was developed for delivery in the lecture environment, and it seems to make sense that correct theory should lead to correct practice. However, for design in general, Snodgrass [8] points out that this does not hold. In fact, rigidly enforcing correct design theory is detrimental to learning design. These assumptions are among the many problems that led to the failure of design education in North American engineering schools.

Instead, design educators must acknowledge that the path to realizing the goals of design education is to provide not only useful methods for doing design, but also to provide opportunities to learn how to manage the activities of design [2]. Therefore, the role of the instructor must also be altered from the traditional lecture and theorybased approach to one that supports an inquirybased approach to teaching and learning design.

If engineering design can be considered to be a performance of engineering involving a high degree of synthesis, the need to differentiate between design practice and design education becomes clearer. In any performance oriented activity (sports, music, art) the student cannot be expected to function at a professional level since the skills they must synthesize in order to perform are not yet developed. The goal of student training is to foster the development of the necessary skills and to provide opportunities to synthesize those skills at whatever level is reasonable [3]. In engineering design, although the concept of a design professional guiding a student through a professional level execution of design is attractive, it is unrealistic. At best, the final design will reflect the knowledge of the instructor rather than of the student. A more effective role for the instructor is to create the environment in which the student can practice and improve the skills of design. The creation of this environment fits quite well into the recommendations put forth by the Boyer Report.: to create a learning environment where instructor and student engage in a negotiated or reciprocal learning relationship where both act as teacher and learner. To accomplish this goal, the instructor needs to stimulate original thought and independent effort in the student. This is a worthy goal both for the vision of the Boyer Commission and for a successful engineering design experience.

\section{Disadvantages of Research Faculty Acting as Design Coaches}

In the traditional lecture environment, however, where the only supervisory contact available to the student is through the expert instructor, original thought and independent effort is very difficult to generate since the students see their own knowledge as worthless in relation to that of the instructor.

In a large design class, where supervision/coaching of design teams must be carried out by persons other than the instructor, the same problem exists when another faculty member is assigned to the supervisory duty. The problem is exacerbated when that faculty member is one whose expertise lies in analysis and not in the synthesis of design. In that case, the students are not only reluctant to develop their own ideas, the ideas they receive from the supervisor are going to be focused on analysis and not on synthesis.

A more effective means of generating original thought and independent effort is to have the supervisor or design coaching duties carried out by properly trained and supported graduate 
students. The role of the design coach is to raise questions, offer suggestions, point to potential methods or resources while allowing the student designers to retain ownership of their design knowledge. These duties do not require knowledge of "the answer" which is the main justification for involving faculty [2].

\section{The Boyer View of Graduate Student Training}

The Boyer report specifically recommends that greater effort be put into training graduate students as apprentice teachers and for other profession roles. Since the goal of many grad students is to work in the university research environment, they will also be working as instructors and should be trained accordingly. In general, universities seem to assume that the exposure of grad students to years of being taught is sufficient preparation for becoming a teacher [2]. Certainly, the practice of exposing undergraduate students to untrained graduate student supervision is less than ideal in any discipline or course.

However, in addition to promoting the proper training of graduate students as apprentice teachers, the Boyer Report also identifies the advantages of the undergraduate/ graduate interaction. Undergraduate students benefit greatly from exposure to pursuers of knowledge at all levels of the university community. When working with graduate students, undergraduate students can see the relationship of their developing skills with respect to those of the graduate student and the comparison is not so over balanced as it is with expert faculty members. Undergraduate students come to value their own knowledge and are more comfortable exposing their ideas to a graduate student supervisor who is more closely connected to their own level of thinking.

Particularly in design, the reciprocal relationship between teacher and student promoted by the Boyer Report creates a significant advantage on two levels:

1. The graduate student supervisors learn about design alongside the undergraduates. Since design competence evolves over time, grad students are able to enhance their own design learning by observing and participating in the struggles of their undergraduate design teams.

2. As the instructor takes on the roll of training the graduate students to teach, the graduate students also educate the instructor as to the day to day struggles of the undergraduate students. This "pulse taking" of the undergraduate students is an invaluable teaching tool in design education and one that is generally unavailable to the expert instructor. The graduate students are operating in a position between that of the student and the instructor and can see connections, problems and solutions that the instructor cannot.

\section{Supporting the Graduate Student as Apprentice Teacher}

The ideal Boyer educational environment is one in which faculty and students are both learners and researchers. Fostering a two way flow of information is central to the creation and maintenance of a healthy intellectual community. This kind of reciprocal relationship should exist between undergraduates, between graduates, and between faculty as well as between the combinations of the three levels.

In the case of graduate students as engineering design coaches, it is important that the instructor create an environment in which the grad student coaches are able to discuss, plan and carry out the day to day activities of the design coach. Although the input of the instructor is vital to keep everyone on the right track, it is the ability of the coaches to work as an autonomous and collaborative unit that maintains the delicate balance between success and failure in the design class.

If students are doing real design work, there is no sense of what the right answer to the design problem might be [7]. Therefore, there is often a high level of discomfort experienced by undergraduate students who are accustomed to text book oriented course work consisting of analytical problems with only one correct answer. In any given real world design project, it is not possible to predict when problems will occur or to anticipate what those problems might be. Therefore, the graduate student design coach must feel empowered to take action in the heat of the moment. By establishing a degree of autonomy within the design coaching team, the instructor can reduce the number of mediations requiring instructor input.

Regular meetings are also required between the instructor and the coaches in order to keep the coaches informed as to the nature and progression 
of teaching goals and to keep the instructor abreast of the many and varied issues that arise in any real design project.

The most effective way to establish the patterns of collaboration and consultation is to begin each term with a short training workshop to give the design coaches an opportunity to bond as a team, to receive an introduction to the overall strategy of the course, practice effective teaching techniques, and to gain first hand experience at the design activities that the undergraduate students will be exposed to.

Within this kind of collaborative framework, graduate students will be able to use their classroom activities to enhance their own abilities to frame questions and seek answers independently. The experience and training they receive will prepare them for research and teaching careers. Their training will also address the common complaint from industry that $\mathrm{PhD}$ 's too often fail as effective communicators and are unable to advance their careers as a result.

\section{The Post-Boyer World}

In 2001, the Boyer Commission completed a second survey focused on the response of American research universities to the recommendation of the 1998 report [5]. In general the following improvements were noted:

1. Emphasis on the teaching of writing, communication and math skills

2. Expand undergraduate research opportunities

3. Establish learning communities

4. Create teaching and learning centres

5. Expand the use of information technology

6. Expand experiential learning initiatives

7. Implement collaborative learning initiatives

However, despite the many advantages of engaging and training graduate students as apprentice teachers, little progress was reported in this area. The 2001 report also indicated that most of the effort to improve the undergraduate environment was directed at the best undergraduate students.

\section{Conclusion}

In eight years of developing undergraduate engineering design programs, we have come out strongly in favour of employing graduate students as design coaches. Properly supervised, graduate student design coaches are more effective than faculty who are not experienced in either design or design education. The benefits to the instructor, the graduate students and the undergraduate students are closely aligned with the recommendations of the 1998 Boyer Commission Report. In Canadian Universities, where we are still plagued with very large classes and inadequate faculty numbers, the function of the design coach is critical to the success of a design program. In fact, the learning community created in the engineering design class between instructors, graduate students and undergraduate students provides the broad base of benefit that, according to the 2001 Boyer report, is still lacking in North American research universities.

\section{References}

[1] Caswell, D.J., Johnston, C.R., Fauvel, O.R., Douglas, D., Eggermont, M. "Fundamentals of a

First-Year Engineering Design and Communication Course: Familiarization, Functionality and Testing", Proceeding of ASEE Conference, Salt Lake City, 2004

[2] Fauvel, O.R., Caswell, D. J., Johnston, C.R., Brusse-Gendre, T., McDonald, C. "Graduate Study of Design Pedagogy" Proceedings of the International Conference on Engineering Design, Stockholm, 2003

[3] Fauvel, O.R., Winkelman, P., "Organization of Technological Information for the Novice Mechanical Designer" International Workshop on Pedagogics in Design Education, International Society for Design Science of Engineering Design, Pilzen, Czech Republic, 1998

[4] Harris, James G., "Journal of Engineering Education Round Table: Reflections on the Grinter Report", Journal of Engineering Education, Jan. 1994, pp. 69-94

[5] Kenny, S. et al, "Reinventing Undergraduate Education: Three Years After the Boyer Report", Boyer Commission on Educating Undergraduates in the Research University. State University of New York and Stony Brook. 1998

[6] Kenny, S. et al, "Reinventing Undergraduate Education: A Blueprint for America's Research Universities", Boyer Commission on Educating Undergraduates in the Research University. State University of New York and Stony Brook. 1998

[7] Rittel, H.W.J., "Impressions of Architecture 130: Notes and Observations of Prof. Horst W.J. Rittel's Classic Design Methods Course at Berkeley as taught circa-1969-1971" Design Methods, Theories, Research, Education and Practice, 1996 Vol 29 no. 1 to vol. 32 no. 4 
[8] Snodgrass, A. "On 'Theorising Architectural Education', Architectural Theory Review: Journal of the Department of Architecture, University of Sydney, Vol. 5, No.2, P. 89-93 